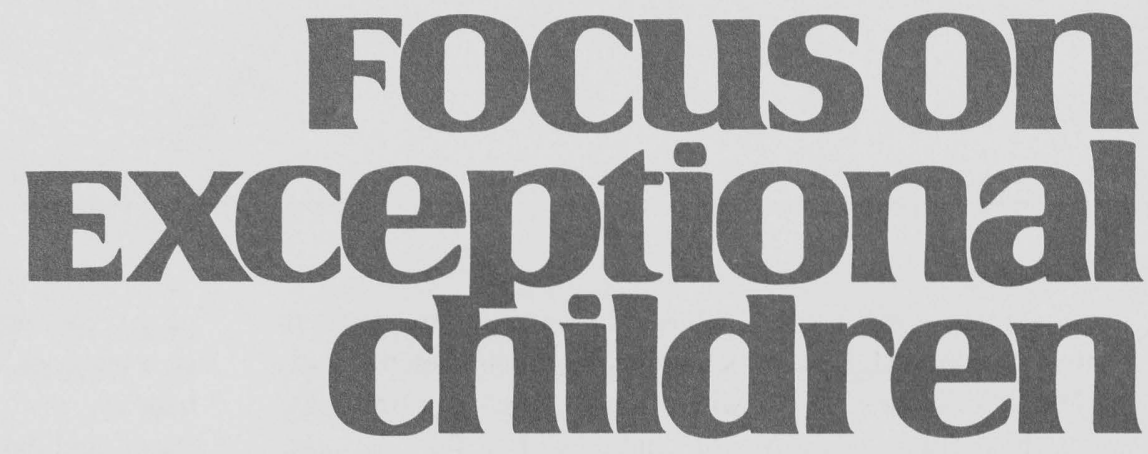

\title{
Teaching Project Team Skills: Enhanced by the WWW
}

\author{
Edward L. Meyen
}

The project model of teaching and learning has stood the test of time. Children and adults alike use it to carry out major tasks. When teachers assign students to prepare group reports or to research a given topic, students typically apply their intuition and form a project team. Unit teaching draws heavily on the project model in that group activities are often central to a unit. Teachers also prepare students for project work by instructing them on how to organize information, define roles, plan, develop timelines, and work cooperatively with peers on routine assignments.

Planning and the division of labor are generally accepted as sound approaches to completing projects that can be taught to students. Students quickly learn the process of assessing an assignment informally and determining what is involved, whether it will be time-consuming, and the several tasks to be carried out. Some students are more adept than others at managing projects and determining how to carry out the planning tasks systematically. Most students, in any case, enjoy the team process of working on projects.

As classrooms gain access to the Internet, the WWW becomes a major resource for teaching projects and building team skills. The dynamics of using the WWW in team projects provide students varied opportunities to participate in meaningful roles. At least one team member has to be skilled in searching and navigating the WWW for sites containing information specific to the project topic. Others can record notes or maintain files on identified sites. As a whole, the group can contribute ideas on key words for searching and make decisions on what information and sites are most relevant to carrying out the team project. Students also may use computers as a tool for building their project reports, whether this means utilizing a word-processing program or even a simple presentation program. Students can teach each other about their respective roles.

The result is that, in addition to pursuing successful team projects, students learn webbased skills that can generalize to other instructional applications and to their personal use of computers. For students with a disability, the WWW presents an array of meaningful ways to contribute to the team process. Each role in researching web sites is important, providing a number of options that require different skills. The benefits derived from assuming these roles can be as important as the content learned from the site.

In general, the project method students use in carrying out class assignments is much like models adults employ in their personal and professional lives: A definable task (or

Dr. Meyen is a professor of special education, University of Kansas, Lawrence. Appreciation is expressed to Cindy Lian, a graduate student in the Department of Speech Language and Hearing at the University of Kansas, for her assistance in researching and preparing this manuscript. 
tasks) is involved, a timeline has to be set, and final products are to be created. Even in situations in which students complete tasks by themselves with minimal assistance from others, they tend to use project techniques. For the most part, this is a matter of gaining control of an assignment and being able to identify and separate specific tasks so they can be pursued individually and collectively to a successful conclusion.

Because project planning skills are generalizable, students should be helped to become proficient in the several roles involved in being an effective team member. Teachers will find that not only are project team skills generalizable to life situations, but they also are generalizable to areas of instruction beyond unit teaching. Students who become proficient in unit-related project work should be encouraged to use their project skills routinely. Research has shown that working in groups promotes (a) reasoning and higher-order thinking; (b) cognitive processing such as rehearsing, organizing, and integrating information; (c) perspective-taking and accommodation to others' ideas; and (d) acceptance and encouragement among those involved (Bossert, 1988-1989).

Attempts have been made over the years to develop sophisticated techniques for utilizing the project model in em-

\section{FOCuson Exceptional children}

ISSN 0015-511X

FOCUS ON EXCEPTIONAL CHILDREN (USPS 203-360) is published monthly except June, July, and August as a service to teachers, special educators, curriculum specialists, administrators, and those concerned with the special education of exceptional children. This publication is annotated and indexed by the ERIC Clearinghouse on Handicapped and Gifted Children for publication in the monthly Current Index to Journals in Education (CIJE) and the quarterly index, Exceptional Children Education Resources (ECER). The full text of Focus on Exceptional Children is also available in the electronic versions of the Education Index. It is also available in microfilm from Xerox University Microfilms, Ann Arbor, MI. Subscription rates: Individual, $\$ 30$ per year; institutions, \$40 per year. Copyright (C) 1998, Love Publishing Company. All rights reserved. Reproduction in whole or part without written permission is prohibited. Printed in the United States of America. Periodicals postage is paid at Denver, Colorado. POSTMASTER: Send address changes to:

$$
\begin{gathered}
\text { Love Publishing Company } \\
\text { Executive and Editorial Office } \\
\text { P.O. Box } 22353 \\
\text { Denver, Colorado } 80222 \\
\text { Telephone (303) } 757-2579
\end{gathered}
$$

Edward L. Meyen

University of Kansas
Glenn A. Vergason Georgia State University

Richard J. Whelan

University of Kansas Medical Center

Stanley F. Love Publisher
Thomas Love Managing Editor ployment situations calling for decision making, efficiency, cost-analysis, and quality control. For the most part, they have involved a technique such as systems analysis and instructional design. These are all compatible with the project model students use. Thus, teachers need to keep in mind that the process they use when working with fellow teachers in carrying out a project, for example, can be taught to their students and that these skills contribute to success as adults.

No one project strategy consistently works best. Certain tasks, skills, and behaviors, however, tend to be most applicable. In this sense, the process is eclectic. This is true particularly with regard to project assignments associated with unit teaching. Not only does it have a definite goal, but the process of achieving the goal also requires students to specify tasks, set time lines, and employ formative evaluation strategies, just as teachers do in their own project work. The skills and knowledge required to carry out projects dictate the need for collaboration and, therefore, a team approach. The number of students collaborating, of course, depends on the scope of the project and the complexity of the activities involved. Although a teacher may assign projects that individual students can achieve, the comprehensiveness of most unit-related projects is such that the combined efforts of a group of students, each bringing different skills to their team are required.

In most cases, students must be prepared to learn new skills in addition to those they already have. When using the WWW as a resource, at least one member of the team has to have sufficient team skills to enhance the team's access to the WWW. As the team uses the WWW as a resource, other team members will become competent in using the WWW. As students gain experience in project work, they develop their skills and, in doing so, fewer new skills have to be taught in pursuing subsequent projects. The following is a sample of a project assignment that might be included when teaching a unit in the primary grades on "Likenesses and Differences."

\section{SAMPLE PROJECT ASSIGNMENT}

An advantage of the WWW is that for almost any topic the web contains a wide array of rich resources. In fact, it is difficult to find a topic that students would not be successful in locating resources on that they otherwise would not have access to. For example, a unit on "Likenesses and Differences" offers many opportunities for project assignments. The grade level will influence the range of topics a project might cover and the complexity of the assignment. At the elementary level, a project assignment might be structured around sensitizing students to differences related to generations. For example, teams might be organized to develop exhibits illustrating the differences in the clothing team members wear today in comparison to the clothing their grandparents wore when they were children their age. 
The advantage of this project assignment is that many team members' grandparents will be living. Some likely will live in the same community. The assignment requires students to agree upon the types of clothing to be compared, and to research. Thus, students will be able to correspond with grandparents or conduct personal interviews to find out what their grandparents wore. Some grandparents even may have some of their clothing from their days as children. Advertisements of clothing in their grandparents' days also will be available for research. By searching for web sites related to the topic of Likeness and Differences, students can include information from foreign cultures.

The project can be carried out in two or three weeks, and it allows everyone to participate. It can be defined easily and offers opportunities to apply communication, reading, math, and problem-solving skills. Because students obviously know what they wear, they can begin their planning by focusing on which clothing items they wish to use for comparison. With some planning regarding memberships on teams, teams can reflect gender and ethnic differences. Also, the class may include some international students or students who lived in other parts of the country previously. They could access web sites from these areas, adding to the richness of the team work. Project assignments should be interesting, allow for students active involvement, and extend students' knowledge base related to the unit topic.

\section{Project Team Skills/Tasks}

Just as adults must possess specific skills to complete projects successfully, students, too, must have certain skills. Although the nature of the project will dictate the specific skills needed and the tasks to be completed, some skills are necessary in carrying out most projects. Students' proficiency in these skills will vary. For example, because of prior experience, some will be prepared immediately to become productive members of project teams. Others may not have some of the needed skills.

Teachers need not wait to engage students in project work until they have the necessary skills, as the skills can be taught effectively as part of the project experience. The first couple of times a project is assigned as part of students' work on units to assess their project skills and develop them further. Most of the skills are not unique to project work. Students likely will have developed them as a consequence of other experiences. The same is true of their computer skills. Projects provide meaningful opportunities for students to apply and refine their computer skills.

A reason for assigning project work, in addition to helping students learn more about the unit theme, is to strengthen project-related skills that will generalize to other learning experiences and to real-life situations. The skills can be taught in isolation, collectively, and through methods and circumstances other than unit or project activities. The skills selected for discussion are well known to teachers. Although some may seem a little advanced for elementary students, appropriate levels of sophistication and application can be stressed. When assessing and teaching project-related skills, teachers will have to take their students' abilities into consideration (Reid, Forrestal, \& Cook, 1989). The following are not presented in a prioritized order. Instead, they are presented somewhat sequentially, as they might be needed in the course of a project, but most of the skills are needed throughout a project.

\section{Defining the project}

The teacher is responsible for defining the project as part of the assignment. In contrast to assigning homework in math or reading, in which the students usually have been working regularly on an activity and, therefore, can anticipate what is required of them in a homework assignment, the situation is different when initiating a project. Regardless of the expected outcome for the project (e.g., a report, a model, a demonstration, an exhibit), students will need more information than a directive. The teacher has to set the parameters of the assignment without limiting the team's creativity. Thus, students should share in defining the project.

If several teams of students are carrying out the same project assignment, the teacher can involve them in discussing the assignment. In addition, the teacher will want them to continue their own discussions in their group concerning the project assignment. The intent of working with students in defining the project is to generate team ownership in the project while team members know they are working within the parameters the teacher has set for the assignment. Prior to choosing topics, teachers will need to do a little research on web sites germane to the project assignment. This will allow the teacher to ensure that the team accesses appropriate information when using key words in a search engine. Also, to provide positive project team experiences in use of the WWW, relevant web sites must be available and accessible.

The following are suggested steps for working with teams of students in defining a project assignment.

- Provide each team a written copy of the assignment.

- Engage students in discussing the assignment and provide them feedback on their interpretation of the assignment.

- Allow the teams to frame questions about the assignment. This will help you assess their understanding.

- Involve all students in a group discussion of what the project might look like, given the assignment. Use a flipchart, chalkboard or computer to record students' suggestions. 
- Demonstrate the location of two or three web sites pertaining to the topic. Allow students to look at them and discuss the validity and relevance of the web sites to their project.

- Before allowing the teams to begin their independent work, check their understanding of the assignment. It is best to have consensus before the teams do any further planning.

- Provide ground rules on when the project is due and an estimate of the amount of time the team will be spending on the project. If the project is to be graded, be certain that students understand whether it will be graded as a team or an individual basis and how grades will be calculated.

- If possible, assign each team a place to store its materials. If the team is using a word processor, have the team create necessary folders and files.

\section{Developing a Plan}

An important aspect of the learning is derived from participating in project planning. Students are called upon to demonstrate their conceptual, problem-solving, communication, analytical, and interpersonal skills while planning the project. Although limited class time does not allow teachers to observe the teams closely in all stages of their project work, they should make every effort to monitor each team closely as the team members develop their plans. This enables the teacher to assess the students' planning abilities as well as their understanding of the unit (project) theme, commitment to the project, ability to work as a team, and how they generalize skills and concepts from other lessons to their project work. The teacher also will be able to determine which students have the potential for carrying out specific roles on their project team.

The nature and amount of planning a project requires depends on the complexity of the assignment and the amount of available time. Preparing a group report requires planning that is somewhat different from designing an exhibit or doing a demonstration. Similarly, the planning necessary for creating a scrapbook, writing a report, or developing an exhibit will differ from what would be useful in planning a skit. Nevertheless, all these assignments would benefit from team planning.

No single set of planning steps is equally applicable. Also, planning is not necessarily sequential in the sense that one must complete planning task " $\mathrm{A}$ " before step "B," even though both must be done. Yet, a general pattern determines a somewhat logical sequence. Thus, although in reality some things are done simultaneously, a logical approach is helpful in teaching planning skills, treating each step as if it were discrete. As student teams gain experience in planning, they begin to acquire planning skills and develop their own strategies. They learn to integrate the planning tasks. What is important initially is to help student teams understand the value of planning and their responsibility to the planning process. They will acquire the intuition skill of making judgments as to when a given task should be done.

Teams should be encouraged to engage all members in the planning process. This may be difficult at first, as students who are inexperienced in planning or lack some of the required skills may be reluctant to participate. Although a goal is to produce a plan, the primary goal is to involve everyone on the team so the project will benefit from the ideas of all team members, who in turn take ownership in the project.

Early in the project students should be helped to adopt a planning attitude. In part, this entails encouraging students to think ahead and anticipate what has to be done. It also involves helping them see the value of being organized. In early discussions on planning with project teams, teachers should capitalize on opportunities to stress personal responsibility. Students should be reminded that the activities must be carried out by the team and that the team consists of them. If someone does not do his or her job, the team does not do its job and the project will not be successful. Depending on the skills of the students in using computers to search the WWW, the teacher may want to talk about the opportunity to learn computer skills by working as a team. Everyone can learn from each other.

During the initial stages of the team planning process, students should brainstorm their project assignment. The team members should be as creative as possible in describing what they would like to achieve in the project and build a list of ideas. Initially, they need not be restrained by more than their understanding of the assignment. Some team members will want to begin developing an outline immediately, or to create a list of tasks to be done, or to ask people what they want to do, or just want to move ahead and get it done. The teacher should encourage the teams to resist such efforts and go through an exploratory stage. After they have generated a lot of ideas with full team participation, they can begin to review the lists and narrow the plan of what they might do in the project.

The teacher should help them be sensitive to unusual and creative ideas that might make their project special. Making a judgment about the value, or even the appropriateness, of some team members' ideas may discourage them from participating. Every team member, particularly those in leadership roles, has to be open and accepting when team members are generating ideas.

Teachers know their students' skills, as well as their personal attributes. Thus, teachers can anticipate who will be most helpful in the planning process and who may be less accepting of ideas that may not seem to be on target. As a result, teachers may need to give more attention to some teams than others early in the planning process to ensure that the teams get off to a good start. 


\section{Preparing a Timeline}

Projects benefit from the development of a schedule or timeline that enhances the completion of activities. This is particularly true of project assignments that stretch over several weeks. Even if not required, a detailed timeline is a good planning strategy and represents an excellent opportunity to teach planning skills. Depending on the age of the students, they may or may not have prior experience in planning, particularly as part of a team.

A timeline:

- illustrates the sequence of planned activities;

- allows students to estimate the feasibility of completing the proposed tasks within the time allowed for the project assignment;

- is helpful in analyzing the specific tasks essential to carrying out the proposed activities;

- provides team leaders a management tool to keep the project moving;

- provides a source of information on how the project team anticipates completing the project (The team can review its timeline later to assess progress.)

- enables the teacher to observe team members as they make decisions (Also, it provides the teacher an opportu- nity to intervene if they seem to be misjudging time requirements.)

- can be developed using simple computer programs;

- results in a road map that all team members can contribute to, understand, and share in the ownership;

- causes students to think through their project.

Students must understand that a timeline or schedule is merely a tool to help plan the project. Developing the timeline is not the project. The teacher has to convey the sequence of major activities to be completed and the estimated time allocated to each activity. In most cases, a simplified timeline that reports the activities, the amount of time per activity, and the beginning and ending time per activity is sufficient.

Many teachers have found it useful to have students incorporate project activities and objectives into a timeline that ends up being integrated within the project plan. This approach allows the teacher to easily assess the students' understanding of the project assignment and determine if the students need guidance, encouragement, or additional help.

If the team is encouraged to use the computer, the teacher can reinforce use of the computer by creating a timeline for the assignment and making it available for students to review on the computer. Teachers can even have different students check team progress against this timeline.

TASK

CLASS PERIOD

\begin{tabular}{|l|l|l|l|l|l|l|l|l|l|l|}
\hline & 1 & 2 & 3 & 4 & 5 & 6 & 7 & 8 & 9 & 10 \\
\hline 1. Identify clothing we wear today & $x$ & & & & & & & & & \\
\hline 2. Find pictures of clothing & & $x$ & & & & & & & & \\
\hline 3. Identify clothes worn by grandparents & & & $x$ & & & & & & & \\
\hline 4. Find pictures of our clothing & & & $x$ & & & & & & & \\
\hline 5. Find examples of our clothing & & & & $x$ & & & & & & \\
\hline 6. Find examples of grandparents' clothing & & & & & $x$ & & & & & \\
\hline 7. Decide on how to display clothing & & & & & $x$ & & & & & \\
\hline 8. Decide on location and display & & & & & & $x$ & & & & \\
\hline 9. Develop display & & & & & & & $x$ & $x$ & & \\
\hline 10. Develop introduction & & & & & & & $x$ & $x$ & & \\
\hline 11. Select staff for exhibit & & & & & & & & $x$ & & \\
\hline 12. Decide on how many exhibits & & & & & & & & & $x$ & $x$ \\
\hline
\end{tabular}

*Students can check which class period is required for completing each task.

Figure 1

Sample Project Assignment

Purpose: To construct an exhibit for the classroom that illustrates the differences between the clothing we wear and the clothing our grandparents wore when they were our age. 
The amount of detail to be included in a timeline depends on the nature of the project and the students' skills. A timeline is developed easily if the team follows a systematic approach in organizing the project. For example, if the teacher (a) states the overall purpose of the project assignment, (b) identifies three or four major goals, and (c) describes an activity for each goal, the place them in sequence without great difficulty, estimating the time required to complete the tasks is more complex. Estimating time requires experience. Teachers may want to ask teams to keep a log of the amount of time they spend completing specific tasks. This makes students more aware of time required for future projects.

\begin{tabular}{|c|c|c|c|}
\hline GOAL & ACTIVITY & START DATES & TIME \\
\hline $\begin{array}{l}\text { 1. Identify examples of } \\
\text { clothing }\end{array}$ & $\begin{array}{l}\text { A. Identify boys'and girls' } \\
\text { clothing today and find } \\
\text { pictures from magazines } \\
\text { and catalogs } \\
\text { B. Determine when grand- } \\
\text { parents were our age } \\
\text { C. Look for pictures of } \\
\text { clothing from the years } \\
\text { our grandparents were } \\
\text { our age }\end{array}$ & $\begin{array}{l}\text { January } 22 \\
\text { January } 22 \\
\text { January } 23\end{array}$ & $\begin{array}{l}1 \text { Class period } \\
\text { Same class period } \\
2 \text { class periods }\end{array}$ \\
\hline $\begin{array}{l}\text { 2. Locate examples of } \\
\text { clothing }\end{array}$ & $\begin{array}{l}\text { A. Bring examples of our } \\
\text { clothes from home } \\
\text { B. Obtain help from parents } \\
\text { in looking for clothing } \\
\text { like the clothing worn by } \\
\text { grandparents }\end{array}$ & $\begin{array}{l}\text { January } 25 \\
\text { January } 26\end{array}$ & $\begin{array}{l}1 \text { evening homework } \\
\text { period and } 1 \text { class period } \\
\text { Weekend assignments; } \\
1 \text { class period to make } \\
\text { final selections }\end{array}$ \\
\hline 3. Organize display & $\begin{array}{l}\text { A. Select clothing and iden- } \\
\text { tify how to display it in } \\
\text { an exhibit } \\
\text { B. Identify ways to display } \\
\text { clothing } \\
\text { C. Make cards to identify } \\
\text { clothes and their age }\end{array}$ & $\begin{array}{l}\text { January } 27 \\
\text { January } 28 \\
\text { January } 29\end{array}$ & $\begin{array}{l}1 \text { class period } \\
1 \text { class period } \\
2 \text { class periods }\end{array}$ \\
\hline
\end{tabular}

Figure 2

Sample Timeline

Purpose: To construct an exhibit for the classroom that illustrates the differences between the clothing we wear and clothing our grandparents wore when they were our age.

timeline merely becomes a way of illustrating (in brief form) the design of the project. The team still must make estimates of the time required to complete each activity.

Another approach to a timeline is to identify the tasks to be completed and to place them in chronological order. Students then can estimate the time required to complete each task. Teams at the elementary level typically find this approach easier, as they are not asked to think about goals, yet, they still must identify activities or tasks.

Whereas students usually will be able to identify tasks and
Figure 1 illustrates a sample timeline based on tasks in chronological order. Class periods are used as a measure, but days, hours, or minutes also could be used. Team members can be engaged in making a decision on what measures are most applicable.

Figure 2 is an example of a timeline format that incorporates a statement of the assignment, goals, activities, and a timeline. Requiring teams to complete a timeline before beginning the project assignment is important unless the project is defined narrowly and can be completed in a couple of class 
periods. Teachers should encourage teams to design their own timeline formats. Giving them an example may be helpful, but teams should be free to be creative. The key is to achieve a useful planning tool.

Team success in employing this approach to developing a timeline depends somewhat on the clarity of the assignment. Teachers should be sure that students understand the assignment before encouraging teams to develop timelines. Because developing timelines is a skill that students need to generalize to future assignments, teachers likely will find it worthwhile to invest time in teaching students to prepare timelines. If teams have already prepared an outline of the project, the timeline will be developed more easily.

\section{Negotiating}

Most students engage in negotiating but are not aware of what they are doing when they negotiate or that they can enhance their negotiation skills in various ways. For example, if they want to accompany a friend to the mall and their parents are reluctant to give them permission, they might offer to be home early and to clean their room or perform some other tasks they know their parents would like done. This is negotiation. Similarly, in school students negotiate with their teacher when they want more time to complete an assignment. Also, they often negotiate with classmates in sports when selecting team members or when they need help bringing something to school from home.

Because they are not aware that what they are doing is negotiating, students usually do not develop their negotiating skills further. Instead, they may resort to coercion or being dictatorial when it is not necessary. Or they may not be successful in negotiating when an alternative solution is really important and achievable.

In carrying out projects, individuals and teams often find themselves having to negotiate. They may need help from the custodian to move desks in the classroom or gain access to some materials. They may find that they have selected the same community resource person as another team did for a given project. These situations all require negotiation to achieve a mutually agreeable situation.

Helping students to appreciate the importance of achieving mutually beneficial solutions is important. This is another skill that generalizes to other teaching/learning situations. Specifically, students working on project teams have to understand the following:

- The conflict may have alternatives. In the case of selecting the same resource person, other resource people may be able to do as well. Or the activity might be redesigned so something else might substitute for a resource person.

- Avoiding conflict is best. If students recognize that they need to negotiate with another team, the first thing to do is to inform the other team so both teams are aware of the potential conflict. Perhaps the problem can be resolved before commitments are made and resistance to negotiating a solution has developed.

- Open communication and sharing of alternatives are desirable places to begin.

- If the other team - or, in the case of individuals, the other person - clearly will be disadvantaged if asked to compromise their position, assistance with the project might be offered as a way to compensate for the disadvantage.

- Sometimes it becomes apparent that the team or individual who recognizes the potential conflict should change rather than attempt to work out a compromise.

- Negotiating is not a matter of winning or losing. It is a process of resolving differences, and creating a win/win situation. Teams and individuals should enter into negotiations with three or four alternative solutions in mind that they can accept if the preferred solution is not achievable.

- Time and energy are important considerations in determining if negotiation is warranted. Individuals or team must assess how much time and energy they are willing to invest in resolving a difference.

- Teachers should encourage students, individually and as teams, to negotiate with them if necessary. If the teacher is willing to enter into negotiation with students, it creates a climate more favorable to negotiation. For example, students may believe they don't have enough time to complete the project. Allowing them to negotiate a new timeline with the teacher can be a good learning experience.

Students should be reminded that, in determining who will do what, everyone is free to negotiate. The idea is not to be disagreeable or to resist doing what someone asks them to do. Rather, each student should be willing to express his or her view and to offer ideas and solutions. Part of developing a strong team is to create an environment in which team members are willing to ask questions, express concerns, and make suggestions. If students have differing views, team members should be comfortable in negotiating a solution.

When searching the WWW on almost any given topic, teams will identify many web sites related to their project. They will need to exercise judgment on the quality of the web site, particularly the validity of the information presented, as well as the relevance of the information to their project topic. Furthermore, the teams will have to decide how to manage the information, to obtain a hard copy of the site, or to bookmark the site electronically, to create folders for each category of information found, and name the files for easy identification at a later date. All these tasks provide excellent opportunities to teach negotiation skills.

Teachers need to work with teams in the early stages to observe the negotiating skills of the teams and individual mem- 
bers. Unnecessary debate or overemphasis on negotiation should be avoided. Negotiation should not become a game or a behavior introduced at every hint of a conflict. Students should be helped to understand that negotiation skills are just another tool they may need in working on their project. In this process, students should not make an analogy between the negotiation applied to working on a project team and labor negotiation, which typically is adversarial. This issue is most likely to come up with middle-school and upper-elementary students, who may be more familiar with the news. If it does come up, the teacher should talk with the students about levels of differences and consequences of differences, as well as formal negotiation versus the informal process that occurs on a project team.

The purpose in introducing negotiating as a project team skill is to teach a new set of skills that are generalizable. Teaching negotiating skills also allows for teaching communication and social skills. The theme-related content should be the context for teaching negotiating skills. Teachers often find that students who have demonstrated leadership skills are the same students who are most adept at negotiating. All students, however, should be allowed an opportunity to develop their negotiating skills.

\section{Coordination}

Coordinating the work of a team is a sophisticated skill for students. Understanding what is expected in completing a task is much easier than understanding how to manage a project. Student teams need to be managed, or at least coordinated. Initially, teachers can monitor the work of teams and perform the management or coordination function. This responsibility, however, must be transferred to the team as soon as team members' ability to coordinate becomes evident. Therefore, teachers should be alert for students who demonstrate a talent for coordinating team efforts. The teacher, for instance, can facilitate the performance of students who assume the coordinator role by stressing the importance of defining roles, developing timelines and assuming responsibility as team members.

A well developed timeline combined with a listing of tasks for team members to complete is a useful tool in helping teams coordinate the work on their project. The teacher's challenge is to guide students in developing coordination skills without becoming controlling or creating dissension among team members. Engaging students in developing a checklist of what has to be done and electing someone to keep track of team progress is a good way to introduce coordination. Team members who have participated in building the list are more likely to understand the importance of each task and the need to keep track of progress.

As team members gain leadership skills, their ability to coordinate a project will emerge. When this happens, the effec- tiveness demonstrated in project assignments increases and more complex projects can be assigned.

\section{Evaluation}

In implementing the project method, teachers have an opportunity to teach students a number of skills that generalize to performance on all subjects. Evaluation is one of those generalizable skills, and it is also an attitude. In many ways a positive attitude toward evaluation is more important than actual evaluative skills. Early in their education students need to feel comfortable in accepting constructive assessments of their performance. They also benefit from being able to look at everything they do in school from an evaluative perspective. For example, they should routinely ask themselves questions such as: Did I do the assignment right? Could I have done it better? Did I do my fair share?

As students gain experience in project work, and as teachers emphasize the importance of students evaluating their own performance, students can develop the ability to evaluate their own performance and the performance of peers on team activities (Pigdon \& Woolley, 1993). What has to be achieved is the development of an evaluative attitude - intuitively being committed to assessing what individuals do as students.

No specific strategies, activities, or skills, if applied in project work, will result in the evaluative feedback that teams need to be successful. Nevertheless, teachers can teach students certain techniques to apply that contribute to forming an evaluative attitude. Project assignments are particularly applicable for teaching evaluation skills and in developing evaluation-oriented attitudes, as the focus of evaluation is primarily on team-produced products versus individual effort. Even so, an introduction to evaluation can be embedded in teaching methods that emphasize personal responsibility. As students understand their responsibilities as individual members of project teams, they begin to acquire the framework necessary for assessing their own performance.

Making the transition from personal responsibility to assessing one's own performance requires that teachers build on the many ways students are responsible in the school setting and outside of school. Teachers have a variety of examples to draw upon depending on the age of the students. The term evaluation need not be used initially. After the first two or three project assignments, specific attention, in the form of devoting class time to working on evaluation in the context of responsibility, may not be necessary any longer. Teachers will need to observe the performance of individual students and teams routinely, and capitalize on opportunities to reinforce appropriate application of evaluation skills and attitudes, or to provide assistance when the behavior is not being applied appropriately (Wilson, 1993).

Depending on the students' ages and their sophistication 
with project assignments, teachers may find a planning model useful for introducing the concept of evaluation. Engaging student teams in designing a graphic model of their project plan causes them to think about evaluation questions.

No particular model works best. What often produces the best results with students who are inexperienced in working on project teams is to talk through with them what is involved in carrying out their project. The teacher might record all suggestions on a flipchart or a whiteboard. After a number of ideas have been suggested, the teacher can involve the team in a process of grouping items under categories, then labeling the categories. With the teacher's guidance, the grouping can be oriented toward development steps that fit into a model. The wording is not as critical as the students' understanding of the steps and the concept of a planning model.

Building the model entails applying evaluation techniques. The teacher should remind the students that, in grouping the ity. Suggestions include the following:

- Be certain that team members understand the assignment and view it as one they must achieve as a team.

- As the team begins to organize itself, provide guidance when necessary as the members clarify their roles and begin to define the tasks they plan to accomplish. Ask questions about what they expect the team as a group, and selected individuals, to do.

- If the project is to produce a product such as a report, an exhibit, or a model, show the team examples developed previously. Review the strengths and weaknesses of the examples. Ask students to speculate on how the model was developed-what the team did as a group and what individuals contributed.

- Make notes on checkpoints where the team might review its work and make a judgment on how well it is doing. Find ways to draw the team's attention naturally to those

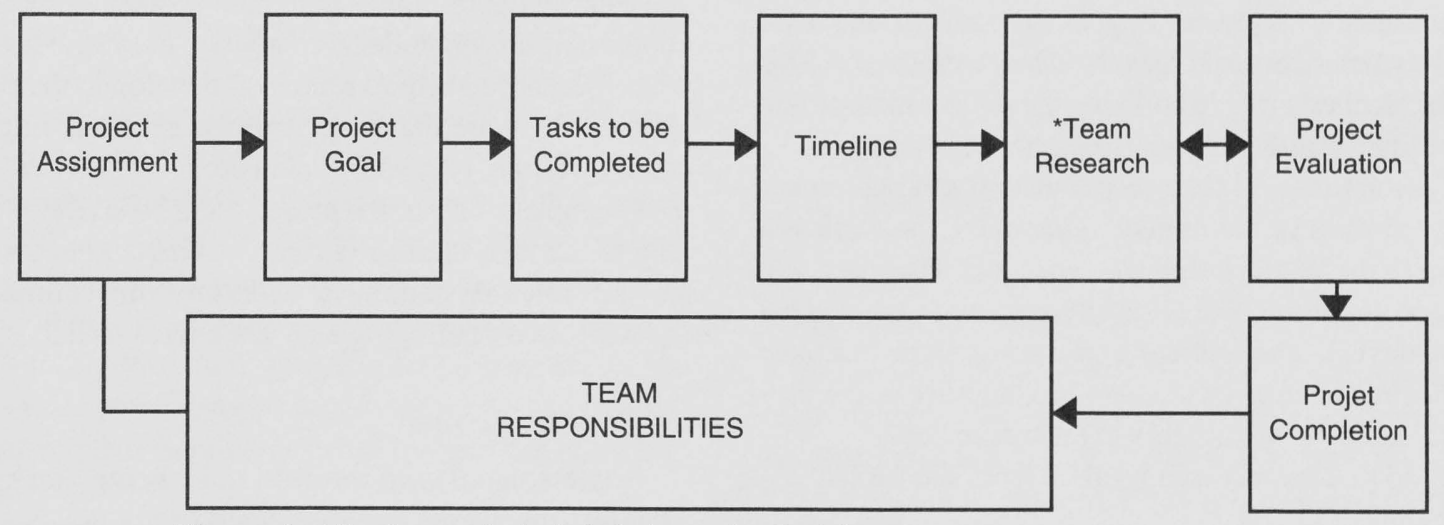

*Research skills also can be included when using the Internet

Figure 3

Student Project Team Model

suggestions, they were making evaluations. In identifying the categories with labels, they again were making evaluations. Figure 3 illustrates a model that might be developed with a student team. The model should be simple and use studentcontributed labels to fill the boxes. Obviously, other configurations could be used to construct a model. Teams should review their model periodically.

\section{Suggestions for providing evaluative feedback to project teams:}

Just as providing feedback on individual performance in unit-related (project) activities is important, project teams, too, should receive feedback. In focusing on teams, teachers must continue to be concerned with the development of responsible behavior on the part of individuals and help students make the transition from personal to team responsibil- stages in the course of the project.

- Provide team feedback. Do not assume that the team benefits when you reinforce an individual for the team's success. Reinforce the team specifically as a group.

- Create opportunities for team members to talk about the progress the team is making and their satisfaction with it. Do this frequently enough so the students do not infer that you are dissatisfied with their efforts.

- If the team has developed a timeline, focus the team's and individual team members' attention on evaluation. Because the team developed the timeline and focused on project tasks as a team, personal implications can be minimized, even though individual roles are embedded in timelines. The timeline was designed to set the direction and to keep the project moving, so checking progress is natural. Teachers also will find that, in some situations, 
the team is making good progress but the students were overly ambitious or naive in setting the original goals.

- Work with the team to set targets for evaluation. These could be written on a flipchart and posted as reminders to the team of when they need to check their progress.

- If team members are to be graded on the quality of the project, engage the team in assessing the quality of what they have produced. First, discuss with the team how the project relates to the original assignment. A major criterion is whether the team has met the intent of the assignment. In addition, it provides a frame of reference for judging the quality of the team's performance in carrying out the project. This strategy is particularly helpful in building expectations for future projects. Try to relate project team performance to real-life situations.

Evaluation is primarily a way to encourage accountability and to influence the quality of work done by teams and individuals. Just as teachers must be accountable for what and how they teach, students are expected to be accountable for their performance as learners. Project assignments allow for accountability behaviors to be developed and reinforced. This is true of the teacher's role in applying the project method and the students' performance as team members.

Teachers must remind themselves of how evaluation/accountability applies to the project assignment, their roles in relationship to the work of student teams, and what they will accept as accountability (i.e., a positive assessment of what the team achieves). The following questions might stimulate teachers to relate evaluation strategies to their use of the project method and their helpfulness to team members:

1. What do you expect as a product from the project assignment?

2. Have you developed criteria for assessing the quality of the product?

3. What are your expectations of the team as a group?

4. What are your expectations of individual team members?

5. What will be your role in ensuring that the project teams progress as you expect?

6. How can you best introduce the concept of evaluation as applied to the project assignment?

7. What will be your benchmarks for assessing team and team-member effectiveness?

The goal of evaluation is to make decisions that contribute to improvement. The challenge in working with student project teams is to keep the focus on improvement and to help students internalize attitudes that reflect a concern for assessing what they do. Evaluation tends to be perceived as personal. At times, this can interfere with learning. In addition, evaluation is continuous in that everything a student does contributes to performance and at some time may be sub- jected to evaluation. Evaluation should not interrupt; rather, it should be incorporated with the teaching/learning process.

\section{Project Team Behaviors}

In addition to the skills required to be good project team members, certain behaviors enhance performance as team members. These behaviors contribute to being active learners and responsible students. While applicable to project work, these behaviors are not restricted to team membership or to project assignments. In many ways they are the same behaviors that make students active learners in all learning situations.

Some would consider these behaviors as leadership skills. Certainly, they represent many of the behaviors that teachers reinforce routinely as desirable student attributes. Yet, they are not necessarily the kind of behaviors for which teaching/learning experiences can be planned. Instead, they are behaviors that teachers need to emphasize in their teaching, be alert for opportunities to reinforce, and, if necessary, create opportunities for students to apply. They also are behaviors that parents can help to teach and develop in their children at home. They are the most generalized of learning behaviors and, therefore, extremely valuable.

Examples of desirable project team behaviors include tending to the task, clarifying tasks, willingness to take risks and to shift roles, developing a "working with" attitude, resource seeking, and developing a communications link.

\section{Tending to the Task}

Some students are referred to as being "task oriented." These students are not distracted easily and have a strong commitment to completing what they are working on or assigned to do, whether it is a project assignment that requires a few minutes or hours or spans several days. Given that the ultimate goal is a quality product completed in an efficient manner, the attribute of assuming responsibility for staying on task and aiding the team in focusing its efforts is essential to the project's success.

This does not suggest that a team member should be allowed to coerce others or cause team dissension. Rather, it means that each team member assumes responsibility for keeping the team on task. At the same time, if members of the team are not contributing to project momentum, but are, instead, inhibiting progress by not carrying out their assignments, they may have to be reminded of their responsibilities to the group and to the project. This responsibility falls to team members.

Much of the responsibility for monitoring team performance belongs to the teacher, particularly in the elementary grades. By demonstrating on-task behaviors, however, stu- 
dents can influence others' performance. In addition, they can be taught how to remind others about doing "their share" of the project.

The ability to stay on task is a personal attribute that can be strengthened. The organization and management of projects should allow for completion of periodic steps so students can derive reinforcement along the way from completing tasks. Teachers can help students develop and enhance their on-task behaviors by stating assignments so the tasks are clear and students can analyze them easily as they plan their project. Students also can be taught to evaluate their progress and benefit from realizing they are doing good work. In addition, teachers should provide feedback to students on their individual and collective efforts.

\section{Clarifying Tasks}

Rarely do team members understand all the tasks to be completed when a project is first assigned. The teacher may view the analysis of tasks as part of the learning to be gained from the assignment. Once the project is operational, a major function of the team becomes one of refining both what is to be achieved and the procedure to be followed. Team members share in the clarification or refinement. In many ways this is an ongoing expectation for project teams. It does not mean that students spend their time challenging the basic concepts underlying the assignment or coming up with ways to change what they are assigned to do. It does mean, though, that as a team member, each student must be sensitive to his or her responsibility to ensure a quality project-and that includes ensuring that they know what the teacher is asking them to do.

In part, this means that assertive behavior is desirable. It also means that the teacher must encourage questioning. Questioning can be directed at the teacher or to team members. Most important, students must learn that, given their understanding of the basic assignment, they share in clarifying and refining what they are being asked to do. This is important in the early stages of initiating a project. If a teacher has successfully engaged students in cooperative learning activities, this behavior is achieved more readily.

\section{Willingness to take risks}

Labeling the willingness to take risks is easier than describing it. In the course of most projects, situations arise in which an action, a decision, or lack of decision should be questioned. Students often are reluctant to raise the question, though. For example, a team member may be especially interested in a specific approach to a solution, and because of his or her enthusiasm, the solution becomes adopted without serious consideration of alternatives. Another example is the case of a project involving collection of data for which one person proposes a data-collection strategy that is too timeconsuming in view of the benefits. Also, the data-collection efforts may be well beyond the team's capabilities to analyze and may be related only tangentially to the project goals. In the creative excitement of project work, students may become carried away in moments of exuberance. Unchecked, these behaviors may lead to problems.

The proposed plans may have considerable face value, which tends to intimidate some students from challenging them. Left unchallenged, however, the plans may result in inappropriate investment of time or talent.

The willingness to raise questions, make observations, and call attention to what is occurring - students being willing to do what they know should be done at the moment -is a form of risk taking. The initial response to a student who questions another might be one of rejection, but, in general, if the questioner is objective and the team is committed to the project, team members will respond by dealing substantively with the suggestion. Obviously, the possibility is inherent that a team member may be offended if his or her actions or ideas are questioned. The teacher must be alert for situations in which a student demonstrates willingness to take risks with the intent of improving the team project. This type of risk taking comes with experience. Once developed, it is an invaluable behavior.

\section{Willingness to Shift Roles}

A common characteristic of successful projects is that the team members are willing to shift roles when necessary to perform tasks that have to be done, even though the particular task might not be part of what they consider their personal responsibility. Project assignments often have a way of growing beyond what students are capable of doing within the available time. Also four or five teams might be working on projects simultaneously. When this is the case, there may not be enough student leadership to ensure the success of each project. The solution is for teachers to work with all students in developing leadership skills applicable to project work. Initially, only six or seven students may have developed leadership skills. Situations will arise in which a student will need help with his or her role and another student might assist or share the role. Teachers need to help students focus on the team effort rather than on a collection of individual efforts.

Another typical characteristic of student projects is the frequent peak times of activities during which materials must be assembled, reports drafted, or other activities brought about by deadlines. These circumstances test the fiber of a team. Students must be flexible in their schedules and willing to accept new responsibilities even if this means delaying something important to their own role as a result of helping a peer or shifting to work on a task that was not assigned to a spe- 
cific team member in the first place. During the life of a project, a number of tasks emerge that are not "naturally" someone's responsibility but nevertheless must be done and become shared. In successful projects even the team leader likely will assume varied roles, some planned and some unanticipated.

\section{Developing a "Working With" Attitude}

Even though the teacher may have to assign project roles, he or she should allow student participation in identifying and developing the roles. Some student team leaders are capable of assigning role responsibilities and managing a project. This is the exception rather than the rule, though. Most student teams require the teacher's assistance in the early stages of project activity. The more experience they gain in project work, however, the more proficient they become. The amount of direct involvement by the teacher depends on the students' abilities and their prior project experience. The key is to ensure that the project team gets off to a good start.

Clarity of the assignment will help, and guidance in organizing the team is also helpful. Teachers want students to view themselves as working with a team toward a common goal. Teachers can identify roles that are compatible with the tasks required to complete the project. The team leader role can rotate, as can other roles. In addition to team leader, others may be referred to as writers, researchers, resource helpers, and even evaluators. Titles for the roles should be meaningful to the age group and the project. Although experience and ability will vary, each student should have the opportunity to learn new roles.

The dynamics of a project are such that, to be successful, a certain esprit de corps has to be established among team members. Hang-ups on roles and titles serve only to interfere. Teachers need to observe teams closely and be alert to abuses of authority and examples of individuals failing to fulfill their responsibilities. Collaboration and cooperation should become the primary attributes of good team membership. Each team member should consider other members as resources and perceive himself or herself as a resource to the team. Then the team should be helped to maximize its members as resources by fostering good relations. This is a personal, as well as a team responsibility. A sense of ownership often emerges in student projects. Once this happens, the "working with" attitude is achieved.

\section{Resource Seeking}

Rarely is a project self-contained in regards to all of the resources needed to complete it successfully. Even if the teacher has planned the unit extensively and the students are familiar with it, the project teams will have to know how to locate the resources they need for their project. Good team members quickly become sensitized to the need for resources and for sources.

Resources are defined as people with specific talents or expertise, as well as materials, references, things, and artifacts. The WWW represents a new resource requiring specific skills to access. If the selected unit has a good theme and the project is of interest to the students, each team member will have ideas about needed resources. The students also are likely to have ideas about where to begin in searching the WWW. A related team behavior is the ability to make judgments about what is or is not a good resource before recommending it to the team. This is particularly true of people the team may wish to invite to class.

\section{Developing a Communications Link}

One of the most difficult tasks a project team faces involves communication among team members and communicating with other project teams about the nature and progress of the project. The latter may not be important, depending on teacher expectations. Nevertheless, requiring teams to keep other teams informed of their progress can be an effective learning experience. Although informal newsletters, written reports, and presentations will help, they are time-consuming and have limitations. Team members who are knowledgeable about the activities and goals of their project can be assigned communication responsibilities to work with other teams. If the students have access to the needed skills or web site editor programs, creating home pages on the WWW may be helpful in enhancing communication. Students can post examples of their work, share information, clarify questions, and inform each other of their progress. The visual feedback and asynchronous communication that is possible through electronic mail and home pages can also motivate students.

Communication among team members is critical. Devoting instructional time to developing communication skills will contribute to the project's success. Teachers who employ communication and interpersonal skills routinely in their teaching will find that their students generalize these skills to project work.

\section{SUGGESTIONS FOR TEACHING USING THE WWW}

If the teacher and students have access to, but not have much experience in using the Internet, project work is an excellent opportunity to begin using the WWW as a resource in teaching. Teachers will experience immediate success in searching for web sites applicable to project topics. Most important, they find web sites that far exceed their expectations in what they offer to students. Teachers who are concerned 
not only with teaching students new skills and adding to their knowledge base but also desire to enrich their lives will realize quickly the instructional potential of the WWW. Some cautions are in order though. The teacher should check out URLs before recommending any to a project team. Some may have reasonable names but not present appropriate content. These situations are rare, but they do arise. Students need some guidance in developing their initial list of key words for conducting their searches. In addition, some URLs may move or be removed from the web.

New resources regarding how to use the Internet and the WWW in project teaching are appearing regularly in the literature. Most focus on resources related to subject fields and topics of interest to students. They are directed to the teacher and offer suggested lesson plans in addition to recommended web sites. The following are a few references that provide suggestions and resources for immediate use in the classroom. They also include specific web sites. These will help teachers develop a list of relevant web sites they can use daily in teaching. Most important, this will introduce teachers to opportunities that will add life to project assignments and enhance the teaching of project team skills. The following are all published by Classroom Connect Inc., Lancaster, PA. http://www.classroom.net

- Classroom Gallery, Grades K-6. (1997).

- Teaching Language Arts with the Internet, Grades 7-12. (1997).

- Web Guide, Grades K-6. (1997).

- Teaching Grades K-12 with the Internet. (1997).

- Teaching American History with the Internet, Grades K-6. (1997).

\section{SUMMARY}

Unit teaching is an excellent vehicle for project assignments. Most unit themes allow for project work. Student projects, like unit teaching, allow for the teaching of academic skills, as well as information about themes. Just as teachers are encouraged to integrate academic skills into the teaching of each unit, they also are encouraged to develop project assignments that enhance the learning of academic skills. Having organized project teams and assigned projects, teachers can create opportunities in subject-matter classes for students to reinforce the application of academic skills in the project work.

\section{ACTIVITIES}

1. Select a unit topic and describe a project assignment. Prepare the assignment in written form, and target it to students at a specified grade level. After completing a draft, ask a colleague to review the assignment and share his or her interpretation of the assignment with you. After revising the assignment based on this feedback, share the revised version with a student at the grade level for which the assignment is intended.

2. Construct a timeline format for students at the grade level you teach. Include in the format provisions for the following:

a. The unit topic

b. The detailing of tasks

c. The time required per task

d. Who is responsible for completing each task

3. Create a simulation for students that calls for a team to negotiate a modification in its project assignment. First develop an assignment description. You could use the one developed in response to Activity 1. Define a plausible reason for modifying the assignment. Have students develop their rationale for the changes and illustrate how they would make their case to their teacher. Give feedback to the team on the rationale and on their presentation.

4. Using the sample project team model in Figure 3 as a reference, prepare a written description of what you believe is the intent of each box in the model. Use language appropriate to the grade level of students you will be teaching. Search the WWW for 10 web sites containing information pertaining to your project assignment. Rank-order them in importance, and describe each briefly.

5. Make a list of 25 key descriptor terms that would help students in searching the WWW to locate information related to your project assignment topic.

6. Use a camcorder to videotape an exhibit or other display or product that represents the outcome of a project. Show the video to two groups of students, but not to the students who produced the project product. Ask each team to evaluate the product, identifying the positive and negative features of what the video portrays. Guide the students in their discussion so they understand that positive and negative observations are both examples of evaluation. Help them understand that the role of evaluation is to help them improve. Ask them to suggest ways in which the product could be improved. 


\section{REFERENCES}

Bossert, S. T. (1988-1989). Cooperative activities in the classroom. In E. A. Rothkopf (Ed.), Review of research in education, 15, pp. 225-252. Washington DC: American Educational Research Association.

Pigdon, K. \& Woolley, M. (1993). A planning model. In K. Pigdon \& M. Woolley (Eds.), The big picture (pp. 19-35). Portsmouth, NH: Heinemann.

Reid, J., Forrestal, P., \& Cook, J. (1989). Small group learning in the classroom. Portsmouth, NH: Heinemann.

Wilson, J. (1993). Assessment and evaluation. In K. Pigdon \& M. Woolley (Eds.), The big picture (pp. 73-94). Portsmouth, NH: Heinemann. 


\title{
Excellence in Educating Gifted \& Talented Learners
}

\author{
Third Edition \\ Joyce Van Tassel-Baska
}

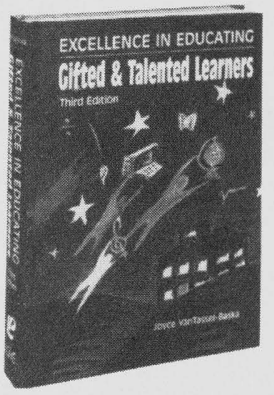

This unique book is brightly written and addresses the key issues and ideas in educating the gifted and talented population. You'll find it covers personality types and learning styles plus stages of giftedness from infancy to adulthood. It not only gives the characteristics and needs, but discusses grouping and acceleration and offers a comprehensive model of program development. Special attention is given to mathematics, science, social studies, and the humanities. This text translates the latest research into strategies and methods that work.

\section{Special Features}

- Interweaves the characteristics of the gifted with program development and curriculum

- Explores thinking skills and creativity

- Includes new ideas for grouping students

- Covers both cognitive and affective needs

- Packed with new ideas for curriculum modifications

9706/hardback/544 pages/\$58.00/ISBN: 0-89108-255-7

\section{EXCELLENCE IN EDUCATING \\ GIFTED \& TALENTED LEARNERS}

Please send me copies at $\$ 58.00$ per copy

Name

Address

Method of Payment

Check Enclosed

Purchase Order Number (attach copy of PO)

Charge to: Visa MasterCard Card Number

Name on Card Expiration

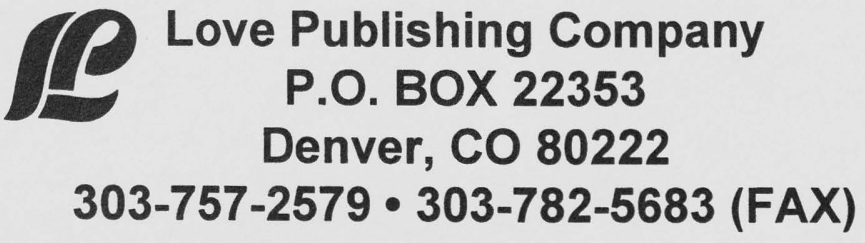




\section{Professional update}

Learing Disabilites Association of America

March 11-14, 1998

Hilton Hotel

Washington, DC

Contact: Learning Disabilities Association of America 4156 Library Rd

Pittsburgh, PA 15234

\section{Council for Exceptional Children}

April 15-19, 1998

Annual Conference

Minneapolis, $\mathrm{MN}$

Contact: Council for Exceptional Children

1920 Association Drive

Reston, VA 22091

\section{National Association of School Psychologists}

April 14-18, 1998

Annual Conference

Orlando, FL

Contact: National Association of School Psychologists 4340 East West Highway

Suite 402

Bethesda, MD 20814

\section{PERMISSIONS AND COPYRIGHT}

All rights are reserved. No part of this publication may be reproduced, photocopied, faxed, stored in a retrieval system, or transmitted, in any form or by any means, electronic, mechanical, recording or otherwise, without the prior written permission of the publisher.
Back issues are available for sale. Reproduction requires permission and payment of fees. It is illegal and a violation of federal copyright law to reproduce this publication without permission. Direct all inquiries to the permissions editor. 